\title{
Obtenção de pellets por extrusão e esferonização farmacêutica. Parte I. Avaliação das variáveis tecnológicas e de formulação
}

\author{
Helton Max Massaranduba Santos*, Francisco José Baptista Veiga, Maria Eugénia Tavares de Pina e \\ João José Martins Simões de Sousa
}

Centro de Estudos Farmacêuticos, Faculdade de Farmácia, Universidade de Coimbra

*Correspondência:

Helton M.M. Santos

Centro de Estudos Farmacêuticos

Faculdade de Farmácia

Universidade de Coimbra

Rua do Norte, 3000

Coimbra, Portugal

E-mail: helton@ci.uc.pt

\begin{abstract}
O processo de peletização consiste na aglomeração por via úmida de pós de uma substância ativa e excipientes sob a forma de unidades esféricas. Estas unidades esféricas, denominadas pela expressão anglo-saxônica pellets, diferem de grânulos obtidos pelo processo clássico de granulação no que respeita às características fisicas conseguidas. Um dos processos de peletização usualmente empregado para a produção de pellets consiste em duas operações unitárias fundamentais: a extrusão e a esferonização. O presente trabalho pretende apresentar uma revisão da técnica de extrusão e esferonização para produção de pellets farmacêuticos abordando as implicações dos aspectos tecnológicos e de formulação que envolvem este processo.
\end{abstract}

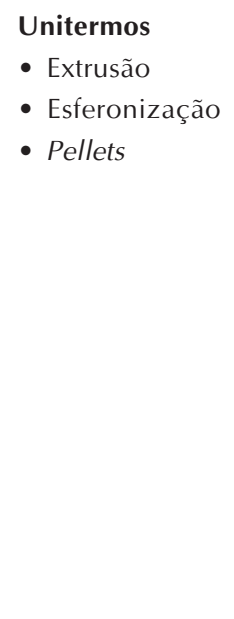

Unitermos

- Extrusão

sferonização

- Pellets

\section{INTRODUÇÃO}

A administração oral de uma forma farmacêutica é a via mais usual, confortável e conveniente para a liberação de uma substância ativa no organismo.

Dentre as diversas formas farmacêutica para a via oral em que os sistemas de liberação de uma substância ativa podem ser concebidos, os pellets têm despertado crescente interesse devido às diversas vantagens tecnológicas e terapêuticas apresentadas (Reynolds, 1970; Bechgaard, Hegermann Nielsen, 1978; Eskilson 1985; Dietrich, 1989). Salientam-se as suas ótimas propriedades de escoamento, devido, principalmente, à forma esférica, estreita distribuição de tamanho de partículas, superfície suscetível ao revestimento por película com interesse à proteção entérica ou à liberação controlada ou sustentada, incorporação de grande quantidade de substância ativa e de substâncias ativas incompatíveis numa mesma forma farmacêutica, grande dispersão no trato gastrintestinal e conseqüente redução da irritação do trato por fármacos gastro-irritantes e baixo risco de efeitos adversos por superdosagem.

O processo de produção de pellets, denominado peletização, consiste na aglomeração de pós finos de substância ativa e excipientes em pequenas unidades esféricas, assim denominadas pellets. Estas unidades esféricas diferenciam-se do produto obtido no processo de granulação clássica não apenas no que respeita ao processo pelo qual são produzidas, mas também pelas características físicas apresentadas.

O interesse pela utilização de pellets como forma farmacêutica remonta à segunda metade da década de 1940. Em 1952, a Smith Kline \& French $(S K F)$ lançou no mercado uma nova forma farmacêutica, o Spansule, que consistia em cápsulas cheias com pellets revestidos que dissolveriam a tempos diferentes. Os pellets eram produzidos por revestimento em camadas a partir de núcleos de açúcar por uma técnica até então não empregada na in- 
dústria farmacêutica. Apenas em 1964, a SKF introduziu uma nova técnica para a produção de pellets de liberação sustentada, que se baseava no congelamento por pulverização de uma solução líquida de lipídios e principio ativo (Lantz et al., 1964). Foi nesta mesma época que surgiu no Japão uma nova técnica para a produção de pellets baseada na esferonização de material cilíndrico, obtido por processo de extrusão de massa úmida de substância ativa e excipientes (Nakahara, 1966). Assim, deu-se início ao desenvolvimento da técnica de extrusão e esferonização farmacêutica. Este processo teve suas primeiras descrições com aplicação farmacêutica no ano de 1970, em duas publicações clássicas (Reynolds, 1970; Conine, Hadley, 1970).

A técnica de extrusão e esferonização, apesar de ter como produto grânulos esféricos, difere da granulação no que diz respeito ao tratamento dado à massa úmida de pós finos de substância ativa e excipientes bem como nos equipamentos empregados. Esta técnica é constituída basicamente por quatro operações unitárias, especificamente, a malaxagem, a extrusão, a esferonização e a secagem.

Este trabalho apresenta revisão da literatura sobre a técnica de peletização por extrusão e esferonização farmacêutica, salientando-se os aspectos tecnológicos e de formulação e suas implicações no processo e no produto final. Constitui, ainda, a primeira parte de uma série de dois trabalhos. Em trabalho subseqüente serão abordadas as características físicas de pellets e as diferentes técnicas de determinação destas características.

\section{PROCESSO DE EXTRUSÃO - ESFERONIZAÇÃO}

\section{Malaxagem}

A malaxagem é a primeira operação unitária no processo de peletização por extrusão e esferonização e consiste no preparo da massa umidificada para a extrusão. A malaxagem é precedida pela mistura dos pós secos de substância ativa e excipientes. Uma vez obtida a mistura homogênea dos pós, segue-se a adição do líquido de granulação e obtenção da massa umidificada. A malaxagem torna-se necessária para produzir massa para compactação por extrusão pelo aumento do tamanho das partículas, diminuição da quantidade de pós em suspensão, melhorando, assim, o fluxo durante o processo. O líquido de granulação deve ser compatível com todos os componentes da mistura de pós e a sua quantidade deve ser aquela que garanta massa umidificada, de consistência ideal para a extrusão e, por conseqüência, a obtenção de um produto intermediário, o produto de extrusão, de características físicas ideais para a esferonização.
Durante a malaxagem deve-se assegurar o mínimo de perda de umidade da massa por evaporação. Para isto, o tempo e a velocidade de malaxagem devem ser controlados a fim de evitar aumento significativo da temperatura, podendo-se recorrer à refrigeração do recipiente em que se realiza o processo (Baert et al., 1991). A aplicação de altas forças para a granulação pode necessitar de grandes quantidades de água para o sucesso do processo (Schimidt, Kleinebudde, 1999).

O controle do tempo e da razão de mistura da massa úmida deve, também, garantir a distribuição homogênea do líquido de granulação. A certificação da distribuição homogênea do líquido pode ser conseguida através do armazenamento da massa umidificada em bolsas plásticas devidamente seladas em condições ideais para evitar perdas por evaporação ou deterioração até o prosseguimento do processo de extrusão (Bains et al., 1991; Fielden et al., 1989; Fielden et al. 1992a; Fielden et al., 1992b; Fielden et al., 1993; Pinto et al., 1993; Sousa et al., 1996).

\section{Extrusão}

A extrusão é a fase do ciclo de peletização por extrusão e esferonização, em que a massa umidificada sofre compactação, sendo modelada sob a forma de cilindros de aspecto semelhante a "espaguete" de diâmetro uniforme. A extrusão pode ser descrita através da aplicação de equações teóricas que caracterizam o fluxo de massa durante o processo. Esta descrição pode ser altamente valiosa para o entendimento da formulação de sistemas farmacêuticos e para este efeito deve-se utilizar um extrusor adequadamente instrumentalizado.

A extrusão tem início com a alimentação da massa umidificada no interior do aparelho de extrusão. A massa é forçada a passar por uma rede ou placa de orifícios de raio $(\mathrm{R})$ e comprimento $(\mathrm{C})$ definidos. Devido à geometria dos orifícios da rede ou placa de extrusão, o comprimento do produto de extrusão irá variar consoante as características físicas da massa de extrusão e da finalidade a ser dada ao mesmo. Para esta finalidade a literatura descreve diversos tipos de extrusores (Hicks, Freese, 1989; Swarbrick, Boylan, 1992). São eles:

\section{Extrusor de parafuso-sem-fim (parafuso de Arquimedes)}

É composto por um parafuso-sem-fim, cuja finalidade é conduzir a massa umidificada até a rede de extrusão exercendo pressão, que força a passagem da massa através dos orifícios da rede. Este extrusor permite trabalhar com quantidades contínuas de alimentação e a utilização de redes de extrusão de diferentes razões C/R. O dispositivo em forma de parafuso de Arquimedes permite o 


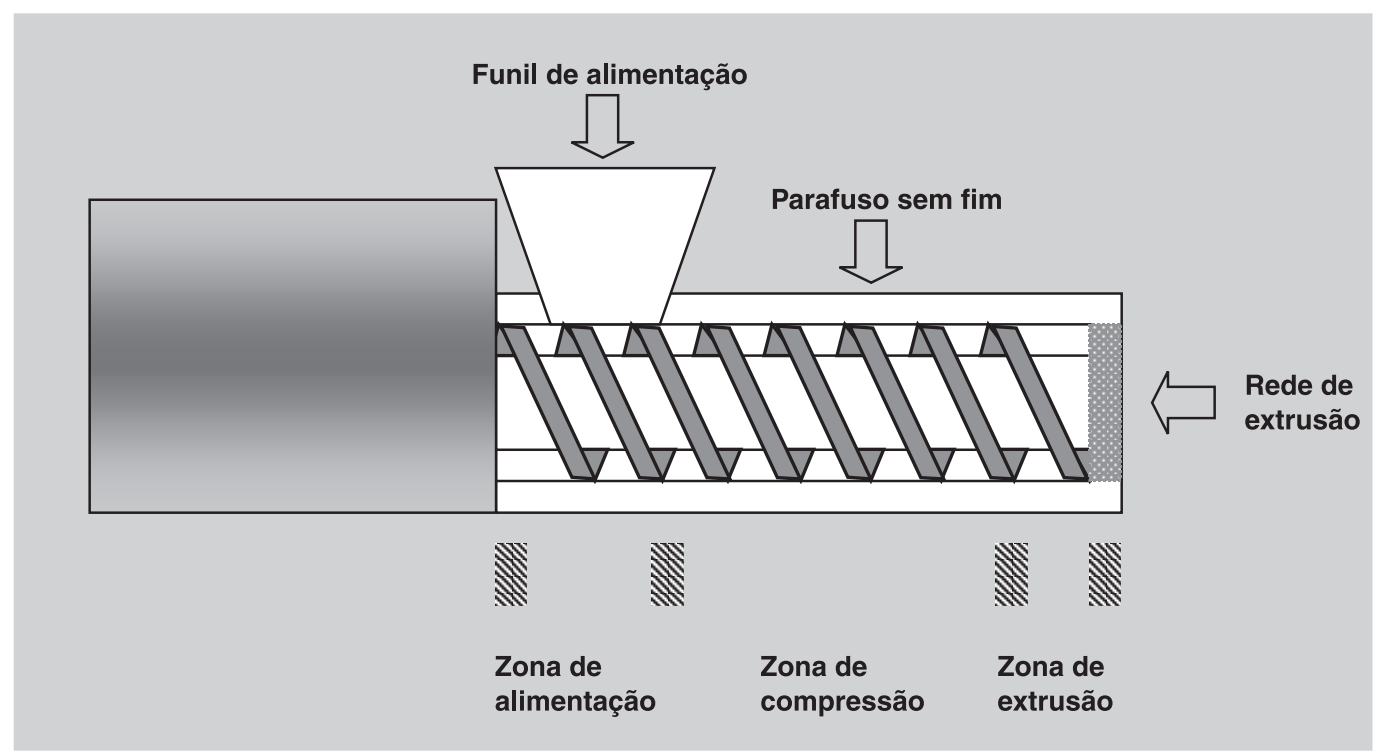

FIGURA 1 - Vista lateral da representação esquemática do extrusor de parafuso-sem-fim axial (adaptado de Hicks, Freese, 1989).

transporte da massa umidificada desde a zona de alimentação à zona de extrusão e pode ser de tipo simples ou duplo (Kleinebudde, Lindner, 1994). O mecanismo de duplo parafuso tem a vantagem de melhor transportar a massa umidificada, enquanto que o mecanismo de parafuso simples resulta em produto de extrusão mais compacto, portanto, mais denso. A geometria do parafuso também pode variar de acordo com a compressão pretendida. Um extrusor do tipo parafuso de Arquimedes pode trabalhar sob os mecanismos axial ou radial em relação ao posicionamento da placa de extrusão (Figure 1,2).

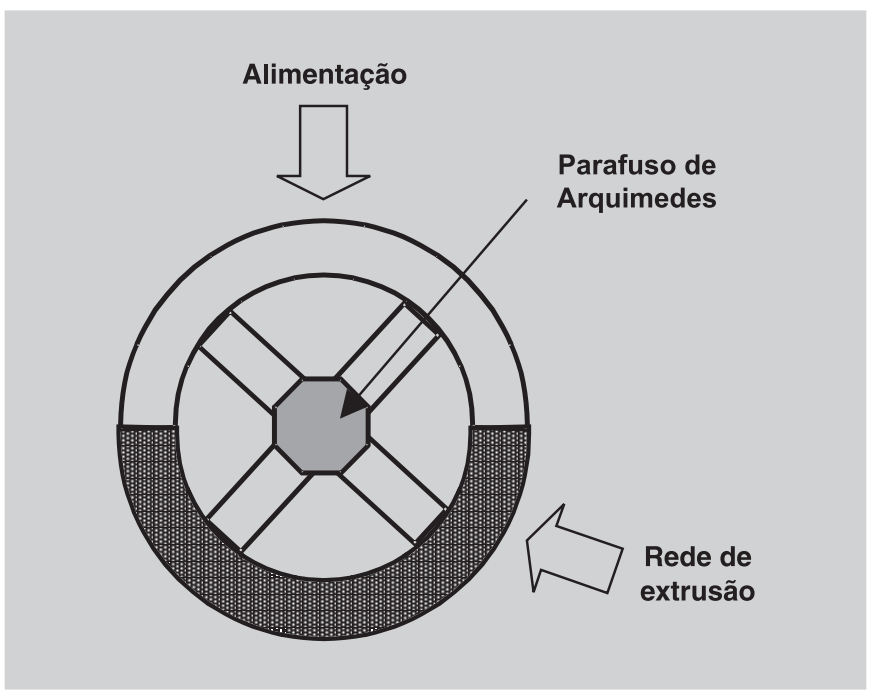

FIGURA 2 - Vista frontal da representação esquemática do extrusor de parafuso-sem-fim radial (adaptado de Hicks, Freese, 1989).

\section{Extrusor de cesto e extrusor de tamis}

Apesar de bastante semelhantes, estes dois tipos de extrusores diferenciam-se entre si tal como as versões axial e radial do extrusor de parafuso de Arquimedes. No extrusor de tamis um mecanismo rotatório ou oscilatório força a passagem da massa umidificada através da rede ou placa de extrusão localizada na base da câmara de extrusão (Figure 3). A desvantagem deste tipo de extrusor reside no fato de promover baixa compactação em comparação aos demais tipos de extrusores. No extrusor de cesto a rede de extrusão compõe parte da parede vertical cilíndrica da câmara de extrusão. A pressão durante a

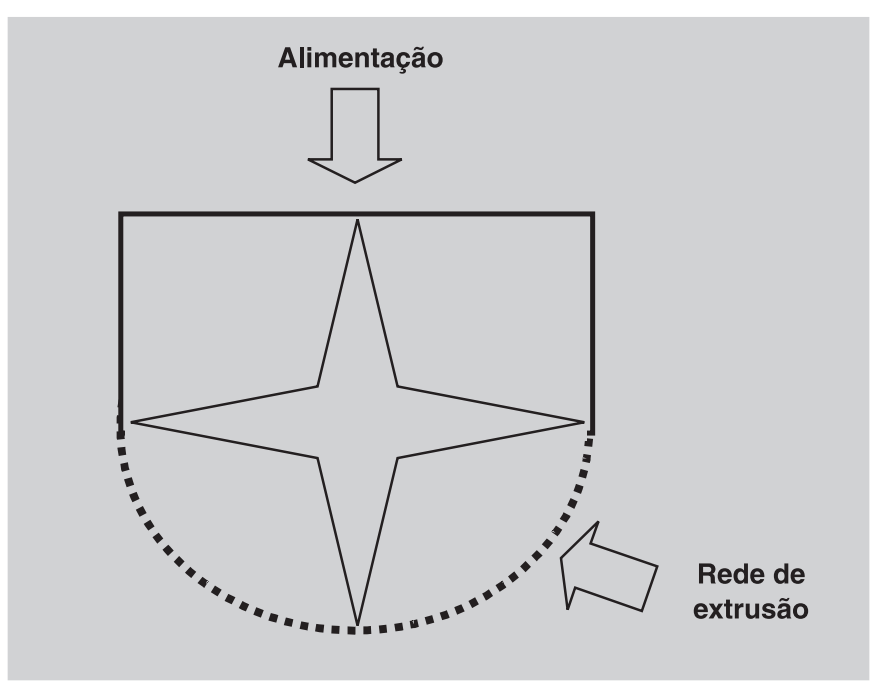

FIGURA 3 - Vista frontal da representação esquemática do extrusor de tamis (adaptado de Hicks, Freese, 1989). 
operação é descrita como semelhante àquela desenvolvida por um extrusor de parafuso com lâminas de extrusão.

\section{Extrusor de rolos}

Descrevem-se três versões para este tipo de extrusor (Figure 4). Uma primeira versão é constituída por uma rede circular perfurada, que gira em torno dos rolos e esses, em torno dos próprios eixos. O sentido de rotação da rede de extrusão e dos rolos é sempre o mesmo. A massa umidificada, que é alimentada para o interior da câmara de extrusão, segue para a superfície interna da rede de extrusão e, durante a operação, a ação dos rolos força a passagem da massa para o seu exterior, através dos seus orifícios, formando, assim, o produto de extrusão. Numa versão deste tipo de extrusor, o rolo encontra-se em posição externa à rede de extrusão ou dois rolos são perfurados e denteados (semelhantes a engrenagens). Uma outra versão é constituída por rolos posicionados sobre uma placa perfurada de extrusão que permanece imóvel.

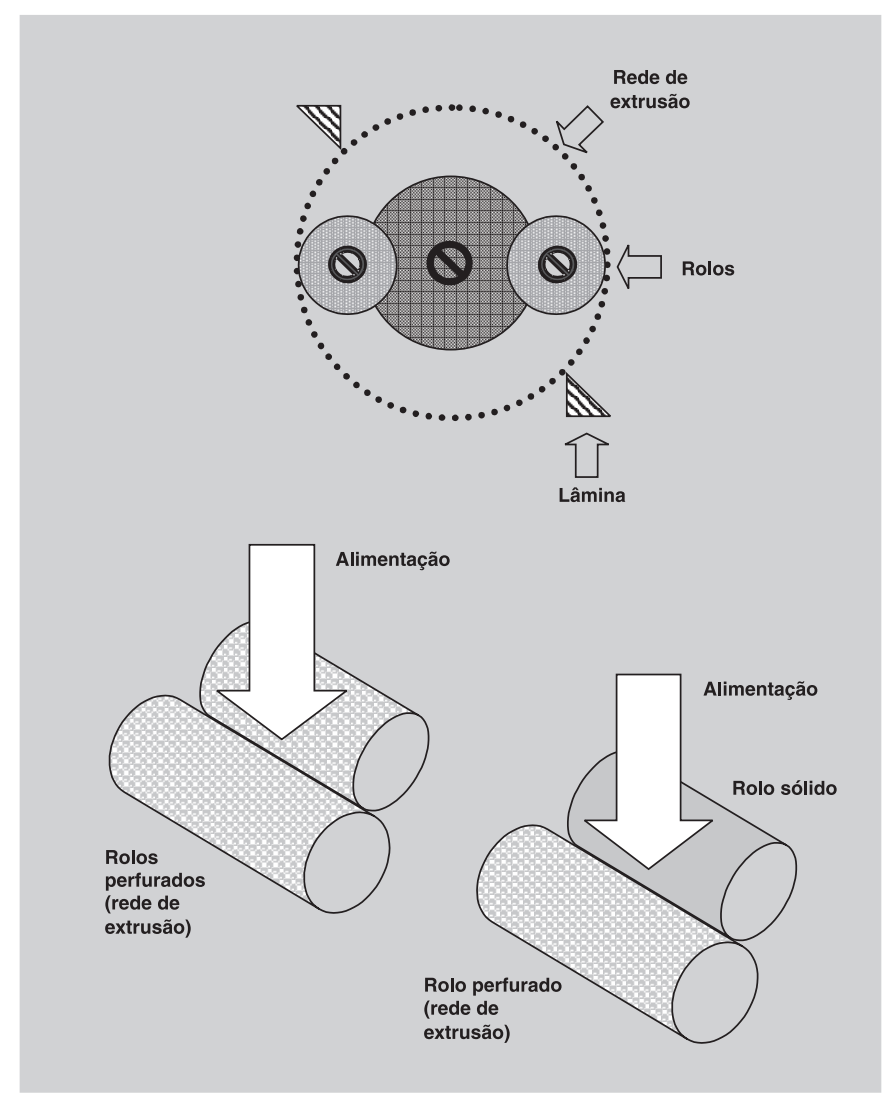

FIGURA 4 - Esquemas estruturais dos extrusores de rolos (adaptado de Hicks, Freese, 1989).

\section{Extrusor de pistão}

Consiste em um sistema cilíndrico e um pistão, que se encontra dentro do corpo cilíndrico que comprime a massa umidificada, forçando a sua passagem através dos orifícios da placa de extrusão (Figura 5). Este sistema opera de maneira não-contínua. O material a ser extrusado é preenchido no cilindro reservatório e parcialmente consolidado por ação do pistão. A extrusão prossegue com a aplicação de uma carga sobre o pistão suficiente para promover a operação.

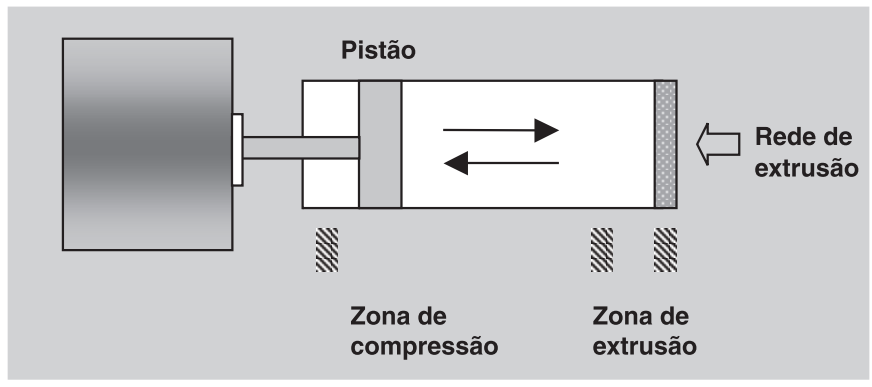

FIGURA 5 - Vista lateral da representação esquemática do extrusor de pistão (adaptado de Hicks, Freese, 1989).

\section{ESFERONIZAÇÃO}

Com relação aos esferonizadores descritos na literatura, todos mantêm a similaridade da configuração, ou seja, uma placa rotatória dentro de uma câmara cilíndrica. O diâmetro desta placa rotatória é variável e conforme a escala de trabalho. Contudo, o trabalho com placas de esferonizações de grandes dimensões pode representar desvantagem, uma vez que a remoção e a limpeza podem ser trabalhosas. Todos os esferonizadores possuem a parede do interior do cilindro lisa e polida. A placa de esferonização pode ser móvel e variar em sua configuração: grelha de ranhuras radiais ou de ranhuras perpendiculares (Figura 6).

Um ciclo típico de esferonização consiste em processar uma quantidade pré-determinada de produto de extrusão até que sejam alcançados a forma e o grau de esferonização desejados. O processo tem início quando,

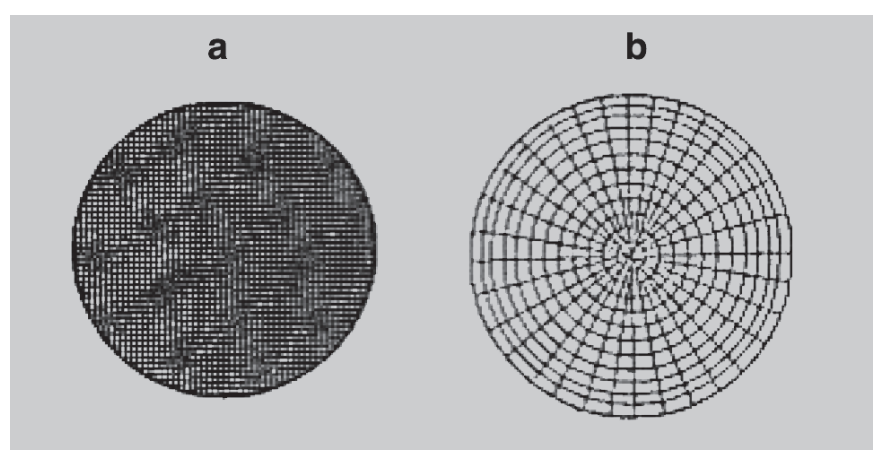

FIGURA 6 - Configuração de placas de esferonização: (a) de ranhuras perpendiculares e (b) de ranhuras radiais. 
por ação da placa de esferonização, o produto de extrusão é quebrado em comprimentos uniformes e gradualmente moldado em forma esférica por processo semelhante à deformação plástica. A esferonização pode ser dividida em diferentes estágios seqüenciados: numa primeira fase o produto de extrusão cilíndrico é quebrado em dimensões menores e de comprimento igual ao seu diâmetro para ter, então, as suas extremidades arredondadas; segue-se a formação de uma estrutura em forma de haltere, que é moldada em forma elíptica e finalmente modelada em forma esférica (Rowe, 1985) (Figura 7a). Um outro mecanismo é sugerido para a formação de pellets (Baert, Remon, 1993) e implica a formação de cilindros de produto de extrusão de extremidades arredondadas, que sofrem torção central e a quebra em duas porções semi-esféricas, que, finalmente, são modeladas e polidas em esferas por ação das forças de rotação e fricção proporcionadas durante o processo (Figure $7 \mathrm{~b}$ ).

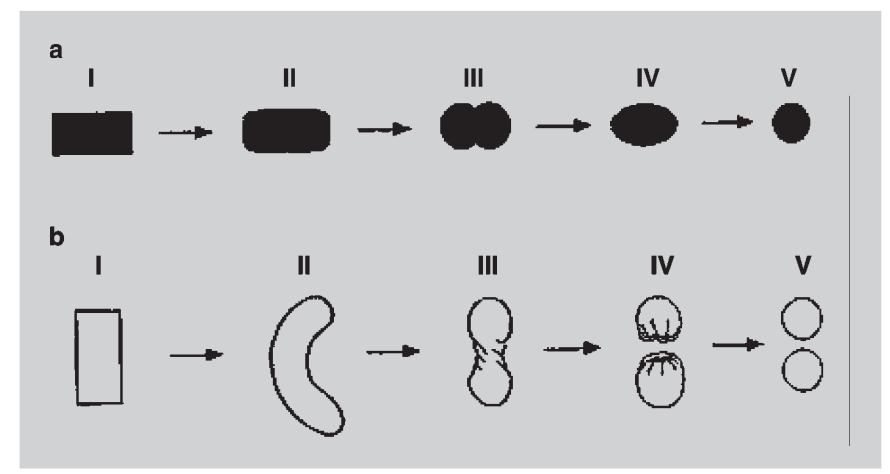

FIGURA 7 - Mecanismos de formação de pellets por esferonização. (a) esquema sugerido por Rowe (1985) I, cilindro; II, cilindro de extremidades arredondadas; III, haltere; IV, elipse; V, esfera. (b) esquema sugerido por Baert, Remon (1993) - I, cilindro; II, corda; III, haltere; $\mathrm{IV}$, esfera com cavidade; V, esfera.

O acúmulo de umidade ou solvente orgânico na parede interna da câmara cilíndrica do esferonizador pode conduzir à aglomeração dos pellets e conseqüente perda do produto. A fim de evitar tal transtorno pode-se dispor de um sistema de aquecimento da parede do tambor de esferonização. A refrigeração da parede da câmara de esferonização pode ser feita quando se trabalha com produtos termossensíveis com o propósito de remover o calor gerado durante o processamento do produto de extrusão. Para remover a umidade superficial das partículas durante a esferonização pode-se introduzir ar seco sob a placa de esferonização. Neste caso a placa deve ser perfurada ou possuir canais ou ranhuras para a passagem do ar seco ou, ainda, o ar seco pode circular no intervalo existente entre a parede interna da câmara cilíndrica e a periferia da placa de esferonização.

\section{Secagem}

Os pellets produzidos na fase de esferonização são prontamente coletados e seguem para a fase final do processamento. A secagem dos pellets pode ser feita à temperatura ambiente ou elevada e em leito estático ou dinâmico. A escolha da temperatura e do leito em que será realizada a secagem irá determinar algumas das características físicas finais dos pellets. Portanto, essa escolha deverá ser criteriosa, devendo-se levar em consideração algumas propriedades físico-químicas dos componentes da formulação.

Para a secagem à temperatura ambiente basta apenas a utilização de uma câmara ou estufa, que permita o controle do ambiente (temperatura e umidade). Quando a opção é a secagem a temperatura elevada em leito estático pode-se também utilizar uma estufa preferencialmente com circulação forçada de ar (quando um solvente orgânico é utilizado para o processamento) ou com um material higroscópico para a absorção da umidade do ambiente de secagem. A opção por uma secagem em leito dinâmico (fluidificado) requer a utilização de um sistema que permita a introdução de ar seco sob pressão e a temperatura determinada dentro da câmara de secagem, promovendo, assim, a secagem do material e produzindo, ao mesmo tempo, o constante movimento deste material (Figure 8).

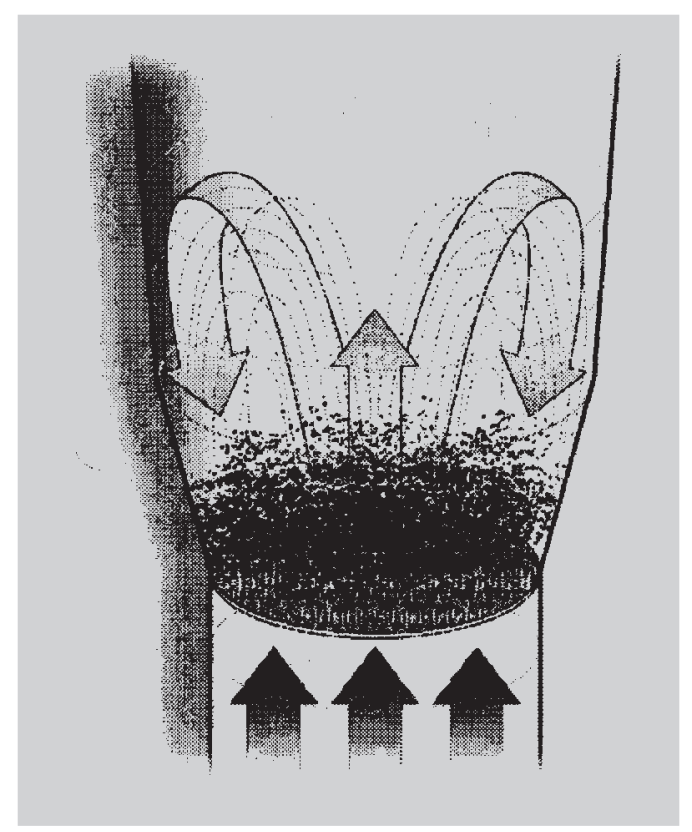

FIGURA 8 - Representação da secagem em leito fluidificado. 


\section{FATORES QUE INFLUENCIAM AS CARACTERÍSTICAS DOS PELLETS}

\section{Matéria-prima}

Os adjuvantes ou excipientes são adicionados a uma fórmula farmacêutica com o propósito de facilitar a produção ou mesmo conferir ou favorecer determinadas características da forma farmacêutica e/ou promover a liberação da substância ativa num sítio específico após ou durante um determinado período de tempo. Portanto, para se ter um produto farmacêutico de características físicas e biológicas adequadas ao seu propósito deve-se incorporar à fórmula farmacêutica excipientes que exerçam funções específicas.

Os excipientes empregados na formulação de pellets são tipicamente aqueles empregados na obtenção de comprimidos ou cápsulas. Considerações devem ser efetuadas pelo formulador a respeito das propriedades físico-químicas dos excipientes e da substância ativa pretendidos para a formulação. O bom entendimento dessas propriedades é crucial para o desenvolvimento de produtos peletizados.

Vários fatores devem ser considerados na determinação do tipo de processo de peletização, a saber, a dose pretendida e as propriedades físico-químicas do fármaco (Sousa et al., 2002). A seleção dos excipientes merece igual consideração, visto que são normalmente os excipientes que levam à formação de pellets de forma, dureza e integridade adequadas.

Para a produção de pellets de boa qualidade é imperativo que a massa inicial possua plasticidade suficiente para produzir um bom produto de extrusão e que este se permita à fragmentação homogênea pela esferonização. Normalmente, para se conferir a plasticidade adequada à massa incorpora-se celulose microcristalina à formulação farmacêutica. A celulose microcristalina é usualmente designada como excipiente de suporte correspondendo tipicamente a $40-60 \%$ da massa dos pós secos da formulação. A qualidade desta celulose microcristalina parece ser fator igualmente determinante para o processo. Alguns trabalhos comparam a utilização de diferentes tipos ou marcas comerciais de celulose microcristalina para a extrusão (O’Connor et al., 1984; Millili, Schwartz, 1990; Jover et al., 1996; Pinto, 1998). A mistura de diferentes tipos de celulose com excipientes e princípios ativos e a avaliação da formação e das características físicas de pellets foram as bases dos trabalhos de Elbers et al. (1992) e Newton et al. (1992). Desses estudos conclui-se que não é possível o intercâmbio de diferentes marcas comerciais de celulose microcristalina. Para este efeito, devem-se ter em consideração as diferentes quantidades de água necessárias para garantir um produto final satisfatório a cada marca comercial de celulose microcristalina. Entretanto, El Saleh et al. (2000) demonstraram que massas úmidas de diferentes tipos da mesma marca de celulose microcristalina (Avicel ${ }^{\mathrm{TM}}$ ) apresentaram o mesmo comportamento durante a extrusão,e a absorção de água foi similar sob as condições experimentais empregadas. As características dos pellets também foram similares mesmo levando-se em consideração as diferenças de tamanho de partículas dos diferentes tipos de celulose.

Em substituição ao uso convencional da celulose microcristalina pode-se recorrer à celulose pulverizada. Sua utilização acarreta a obtenção de pellets mais porosos e friáveis, sendo necessária a associação a um excipiente aglutinante para a obtenção de pellets aceitáveis (Lindner, Kleinebudde, 1994; El Saleh et al., 2000; Alvarez et al., 2003).

Basit et al. (1999) estudaram a possibilidade de produção de pellets de ranitidina com alta ou baixa concentração de celulose microcristalina ou sem este componente na formulação. A alta concentração deste componente permitiu a produção de pellets mais esféricos, mais fortes e menos friáveis. Contudo, os pellets produzidos sem a celulose microcristalina tiveram distribuição de tamanho e forma superiores àqueles produzidos com a celulose.

A utilização da celulose microcristalina também pode ser acompanhada por um polímero hodrófilo visando, assim, à melhoria do processo de extrusão e esferonização por torná-lo menos sensível a pequenas alterações das variáveis de processo, além de melhorar o rendimento e a esfericidade dos pellets resultantes, especialmente quando se pretende incorporar grande quantidade de substância ativa (80\%) à formulação (Funck et al., 1991; Law, Deasy, 1998; Santos et al., 2002).

Quando há o objetivo de se obter pellets com a finalidade de liberação controlada da substância ativa recorre-se usualmente ao revestimento dos núcleos ativos (Sousa et al., 1995a; Sousa et al., 1995b). Isto significa a adição de mais uma operação unitária ao processo, o que, conseqüentemente, acarreta implicações tecnológicas. A fim de contornar esta operação e ao mesmo tempo obter pellets de característicos de liberação controlada da substância ativa semelhantes, ou melhoradas, em comparação àquelas de pellets revestidos, tem-se tentado a incorporação de polímeros ou outras substâncias modeladoras da liberação do fármaco com a finalidade de atuarem como suporte matricial (Goskonda, Sathyanarayana, 1993; Goskonda et al., 1994; Neau et al., 1996, 2000; Varshosaz et al., 1997a; Santos et al., 2002; Sousa et al., 2002b). Vários polímeros hidrófilos de naturezas diversas (deriva- 
dos celulósicos e não celulósicos e os derivados do ácido acrílico) têm sido utilizados com o propósito de servirem como agente gelificante para a fabricação de pellets matriciais. Os trabalhos de Neau et al. (1996 e 2000) exemplificam a utilização do Carbopol ${ }^{\circledR} 974 \mathrm{P}$, um polímero derivado do ácido acrílico, incorporado à formulação com a finalidade de prolongamento da liberação do maleato de clorfeniramina em pellets produzidos por extrusão e esferonização. Polímeros de outra natureza também podem ser incorporados a matriz de pellets com a finalidade de proteção entérica. A utilização do Eudragit ${ }^{\circledR}$ L10055 mostrou-se a mais adequada em comparação ao acetoftalato de celulose e ao ftalato de hidroxipropilmetil celulose devido à formação de matriz homogênea e à produção de pellets de propriedades entéricas sem a necessidade da operação de revestimento (Varshosaz et al., 1997a).

A natureza do diluente utilizado é, também, um fator estudado na formulação de pellets (Fielden et al.,1989; Junnila et al., 2000; Santos et al., 2002a, b, c). Para a seleção de um diluente é essencial que este seja compatível com os demais componentes da formulação e estável para as condições de operação. Os diluentes podem ser de natureza solúvel ou insolúvel em água e fazem parte da composição de pellets com a finalidade de completar o volume ou a massa da formulação, mas, também, acarretam o aumento ou a diminuição da densidade e até mesmo facilitam o processo de formação do pellet. Entretanto, existe a possibilidade de o diluente exceder em suas funções e, assim, contribuir para o aumento da taxa ou duração da liberação do fármaco a partir de pellets. A lactose e o amido são os diluentes usualmente empregados em formulações de pellets. No entanto, outros podem ser utilizados dependendo das características que se deseja conferir aos pellets pretendidos. Por exemplo, o amido de milho ceroso pode ser utilizado como diluente, possibilitando a redução da quantidade de celulose microcristalina numa formulação de pellets para extrusão e esferonização, o que permite a redução dos custos de produção quando se utiliza baixa quantidade de substância ativa (Junnila et al., 2000).

A Tabela I mostra de forma esquematizada alguns pontos relevantes da utilização e influência da natureza da matéria-prima para a produção de pellets.

\section{Líquido de granulação e umidade da massa de extrusão}

O líquido de granulação é necessário para conferir a umidade necessária à massa de pós de uma formulação tornando-a mais coesa e plástica para o processamento e produção de pellets de qualidades aceitáveis. Normalmente a água é utilizada como líquido de granulação (Iyer et al., 1996; Sousa et al., 1996; Varshosaz et al., 1997b), contudo, soluções hidroalcoólicas ou apenas álcool podem ser utilizados com o mesmo propósito (Goodhart et al., 1973; Briquet et al., 1986; Millili, Schwartz, 1990; Elbers et al., 1992; Santos et al., 2002).

A umidade da massa e do produto de extrusão pode ser determinante para o processamento sobretudo na esferonização. A umidade da massa pode ser enquadrada entre limites mínimo e máximo para a produção de pellets. Quando esta umidade é inferior ao limite mínimo, ocorrerá a formação de grande quantidade de pós durante a esferonização do produto de extrusão ou mesmo esferonização incompleta do produto de extrusão devido à insuficiência de plasticidade superficial das partículas. Ou seja, durante a esferonização o líquido de granulação, que constitui a massa de extrusão, migra para a superfície da partícula em formação induzindo a plasticidade superficial necessária para o sucesso da operação. Quando a umidade é excessiva, superior ao limite máximo, ocorrerá migração excessiva de líquido para a superfície do pellet em formação, levando à aglomeração dos pellets uns aos outros e na parede do esferonizador ou, na pior das hipóteses, a aglomeração total da massa. À vista de tal efeito,

TABELA I - Influência da matéria-prima na produção de pellets

\begin{tabular}{lllll}
\hline Materia-prima & Alternativa & Ausência de CMC & Adição de polímero & Adição de diluente \\
\hline Uso convencional de & Uso de celulose & Boa distribuição de & Melhoria do processo & Completa o volume ou massa da \\
celulose microcristalina & pulverizada: & tamanho de pellets. & (serve como aglutinante) & formulação. Facilita o \\
(CMC) como excipiente & Aumenta a porosidade & Diminuição da esfericidade Modelação da liberação & processo. \\
de suporte:40 - 60\% & efriabilidade dos pellets. & e dureza dos pellets. & da substância ativa & Sua influência é consoante sua \\
em peso & Adição de aglutinante: & Aumento da friabilidade & (serve como suporte & natureza. \\
Confere boa esfericidade & Redução da porosidade e & dos pellets. & matricial) & Pode aumentar ou diminuir a \\
e dureza aos pellets. & friabilidade dos pellets. & & Uso para promover a & densidade dos pellets. \\
& & & proteção entérica. & \\
\end{tabular}


há a necessidade de se obter massa úmida de plasticidade adequada para o processamento. Para avaliar a conformidade da massa umidificada, pode-se recorrer à caracterização das propriedades reológicas da massa, uma vez que a plasticidade é uma das características que se relaciona intimamente à umidade da massa (Harrison et al., 1987).

A influência do líquido de granulação na produção de pellets encontra-se resumida na Tabela II.

\section{Tipo de extrusor}

A escolha do tipo de extrusor baseia-se na qualidade e características desejadas do produto de extrusão bem como no destino a ser dado ao produto intermediário. Em se tratando da técnica de extrusão e esferonização, é desejável um produto de extrusão de densidade apropriada à esferonização. Assim, a utilização do extrusor de rolos parece ser adequada a este propósito devido à combinação de extrusão com baixa pressão e desenvolvimento de baixa quantidade de calor e a mínima movimentação de água aliada à alta densificação do produto (Swarbrick, Boylan, 1992; Thoma, Ziegler, 1998b). Um extrusor de pistão instrumentalizado é bastante útil quando se necessita controlar alguns dos parâmetros de processo como a temperatura, o tamanho, a forma, o peso e a densidade do produto de extrusão.

Diversas publicações estudaram comparativamente a utilização de diferentes extrusores (Reynolds, 1970; Rowe, 1985; Fielden et al., 1992b; Baert et al., 1992b; Baert et al., 1993b; Sonaglio et al., 1997; Thoma, Ziegler, 1998a, b; Nürnberg, Wunderlich, 1999a, b). Os estudos comparativos entre extrusores de parafuso nas suas versões axial e radial apresentados por Reynolds (1970) e Rowe (1985) demonstraram a obtenção de um produto mais denso a partir do sistema axial. Para a mesma comparação, Sonaglio et al. (1997) verificaram que o sistema axial produz maior variação de temperatura e maior tempo de extrusão. Por ocasião da análise da influência do tamanho das partículas e a concentração da substância ativa da mistura verificou-se que o tamanho das partículas é um fator importante para o processamento em ambos os sistemas de extrusão, o que sugere que a extrudabilidade da massa não depende apenas de sua plasticidade, mas também do tipo de extrusor empregado. Assim, de acordo com Sonaglio et al. (1997), a escolha do sistema de extrusão de parafuso simples será dependente da quantidade de substância ativa e da solubilidade aquosa deste. Os estudos sobre o processo de extrusão de Thoma, Ziegler (1998a, b) avaliaram as características do produto de extrusão e a influência destas sobre a qualidade dos pellets produzidos a partir de diferentes tipos de extrusores, como o de rolos, de parafuso simples axial e outro radial, revelando que o extrusor de rolos e o de parafuso de sistema radial produziram pellets de tamanho médio e granulometria similares. No entanto, observou-se que os pellets produzidos por intermédio do extrusor de rolos ou o de parafuso simples axial foram significativamente mais densos em comparação com aqueles produzidos por intermédio de um extrusor de parafuso simples radial. Os produtos de extrusão resultantes do extrusor de rolos e daquele de pistão podem não ser equivalentes devido às diferenças de processamento das massas úmidas (Fielden et al., 1992b). A comparação entre as propriedades de esferonização dos produtos de extrusão de mesma massa ternária (celulose microcristalina, lactose e água) obtidos a partir de um extrusor de pistão instrumentalizado e daquele de rolos realizada por Fielden et al. (1992b) exemplifica a possibilidade de utilização do extrusor de pistão instrumentalizado para a avaliação das propriedades de escoamento e esferonização de massa. Verificou-se, também, que se uma determinada formulação pode ser processada num extrusor de pistão em pequena escala, a transposição para uma grande escala num extrusor de rolos é viável. Ou seja, aquelas formulações que necessitam de condições de processo cuidadosas poderão falhar por ocasião da transposição para grande escala.

TABELA II - Influência do líquido de granulação na produção de pellets

\begin{tabular}{lllll}
\hline Líquido de esferonização & Uso de água & Uso de solventes orgânicos & Escassez de umidade & Excesso de umidade \\
\hline Exerce efeito lubrificante. & Uso convencional. & Uso alternativo. & Quando inferior ao limite & Quando superior ao limite \\
Confere plasticidade e & Deve-se dar atenção & Podem-se utilizar soluções & mínimo de umidade: & máximo de umidade: \\
coesão à massa. & à solubilidade dos & de solventes orgânicos. & Formação de grande & Aglomeração do produto de \\
Viabiliza o processo. & componentes. & Deve-se dar atenção à & quantidade de pó. & extrusão. \\
Pode influenciar na & & solubilidade dos componentes. & Falha na extrusão ou na & Aglomeração dos pellets \\
porosidade, dureza e no & & Aumenta a porosidade dos & esferonização & formados. \\
tamanho dos pellets. & & pellets formados. & Formação de bastonetes. & Aglomeração total do produto \\
& & & & durante a esferonização. \\
\hline
\end{tabular}




\section{Velocidade, temperatura e rede de extrusão}

A necessidade de se processar uma fórmula farmacêutica para a produção de pellets de propriedades específicas por extrusão e esferonização pode ser conseguida com pequenas variações nas condições de processamento. Não apenas o tipo de extrusor empregado para o processo, como exemplificado na seção anterior, mas também as variáveis de processo, como velocidade de extrusão, configuração da rede de extrusão e temperatura de extrusão podem influenciar de forma significativa as propriedades do produto de extrusão e, por conseqüência, as propriedades dos pellets, servindo, assim, de ferramenta útil de pesquisa.

Malinowski e Smith (1975) demonstraram que a velocidade de extrusão para uma determinada massa úmida influencia a temperatura desenvolvida na rede de extrusão durante a operação. O aumento da velocidade de extrusão provocou aumento da temperatura de extrusão. Esta observação é de grande importância quando se trabalha com substâncias termossensíveis.

A pressão desenvolvida necessária para a extrusão e a conseqüente densificação do produto intermediário são igualmente influenciadas pela velocidade de extrusão (Pinto et al., 1992; Hileman et al., 1993). Contudo, Hileman et al. (1993) verificaram que para a extrusão de uma dada massa úmida num extrusor de cesto a densidade dos pellets se mostrou independente das condições de extrusão (velocidade de extrusão e razão $\mathrm{C} / \mathrm{R}$ dos orifícios da rede de extrusão). A qualidade do produto de extrusão parece ser amplamente influenciada pela sua velocidade. O aumento da velocidade de extrusão acarreta aumento pronunciado dos defeitos de superfície do produto de extrusão (aspereza e a denominada "pele de tubarão"), que diminuem a qualidade do produto final por promoção da quebra irregular do produto de extrusão durante a operação de esferonização (Harrison et al., 1985a, b).

O efeito lubrificante da água é afetado pela velocidade de extrusão (Pinto et al., 1992). O aumento da velocidade de extrusão dificulta a migração da água através da massa em extrusão impedindo, assim, o exercício do efeito lubrificante desta durante a operação. A configuração da rede de extrusão parece não ter qualquer influência sobre a umidade do produto de extrusão (Malinowski, Smith, 1975). Ainda de acordo com Malinowski e Smith (1975), o aumento do diâmetro dos orifícios da rede de extrusão resulta em pellets de maior distribuição de tamanho, quando conjugada a baixa velocidade de extrusão. Entretanto, a diminuição do diâmetro destes orifícios não mostra qualquer alteração na distribuição de tamanho das partículas. O aumento do diâmetro dos orifícios da rede de extrusão também pode acarretar aumento do volume aparente dos pellets (Sonaglio et al., 1995) e mostra grande influência na friabilidade e na razão de dissolução da substância ativa (Noché et al., 1994).

Pinto et al. (1992) analisaram o efeito do comprimento dos orifícios da rede mantendo-se fixo o diâmetro. Assim, observou-se que para o aumento deste comprimento, com o aumento da velocidade de extrusão, ocorreu aumento da força de extrusão. Neste mesmo estudo observou-se influência mínima do comprimento dos orifícios sobre a distribuição de tamanho dos pellets.

$A$ variação da razão $\mathrm{C} / \mathrm{R}$ dos orifícios da rede de extrusão terá isoladamente efeitos pronunciados sobre a qualidade do produto resultante. A matriz de baixa razão C/ $\mathrm{R}$ promoverá densificação insuficiente e conseqüente formação de produto de extrusão de baixa qualidade ou com defeitos de superfície ou muito sensível às condições de esferonização e variabilidade do tamanho dos pellets.

A influência dos parâmetros de extrusão na produção de pellets encontra-se resumida na Tabela III.

\section{Placa, velocidade, tempo e carga de esferonização}

Diversos estudos da literatura disponível salientam a aplicação de modelos estatísticos para a avaliação das variáveis do processo de esferonização, como a velocidade de rotação da placa de esferonização, tempo de esferonização e carga de esferonização (Miayke et al., 1973; Malinowski, Smith, 1975; Chariot et al., 1987; Bains

TABELA III - Influência dos parâmetros de extrusão na produção de pellets

\begin{tabular}{lllll}
\hline Extrusão & Seleção dos parâmetros & Velocidade de extrusão & Temperatura de extrusão & Rede de extrusão \\
\hline Tipo de extrusor: & & Influencia a qualidade do & Atenção aos componentes & Influência sobre a densificação \\
Grande influência nas & $\bullet$ Velocidade & produto de extrusão. & termossensíveis e à umidade & do produto de extrusão. \\
características do & $\bullet$ Temperatura & Pode elevar a temperatura & do produto de extrusão. & \\
produto de extrusão & $\bullet$ Rede de extrusão & de extrusão. & \\
e dos pellets. & & Atenção aos componentes & \\
& & termossensíveis. & \\
& & & \\
\hline
\end{tabular}


et al., 1991; Hasznos et al., 1992; Hileman et al., 1993; Hellén et al., 1993c, d; Barrau et al. 1993a, b; Noché et al., 1994; Sonaglio et al., 1995). Muitos desses estudos relacionam as variáveis de processo da esferonização de um produto de extrusão com as características físicas dos pellets obtidos. A correlação entre estas variáveis e a qualidade do produto só se torna relevante quando os aspectos críticos que envolvem o processo de extrusão e esferonização são devidamente identificados. Considerando-se a seleção do extrusor um dos fatores críticos, visto que estes não são simplesmente intercambiáveis, o produto de extrusão obtido para determinada massa úmida pode se apresentar mais ou menos sensível às condições de esferonização, consoante o sistema e as condições do processo de extrusão.

A configuração da placa de esferonização é fundamental para o processo, no entanto, não existem estudos que identifiquem sua melhor configuração para a obtenção de pellets de qualidades aceitáveis.

Observa-se que o aumento da velocidade de esferonização se relaciona à diminuição do diâmetro médio dos pellets produzidos concomitantemente ao aumento da produção de pós finos durante a esferonização. A utilização de velocidades muito altas pode resultar na produção de pellets de pequeno tamanho (Malinowski, Smith, 1975; Wan et al., 1993; Sonaglio et al., 1995; Umprayn et al., 1999).

Estudos revelam a influência da variação da velocidade de esferonização sobre densidade, friabilidade, propriedades de escoamento, dureza, esfericidade, porosidade e morfologia superficial de pellets. A otimização da velocidade de esferonização, entre aquela insuficiente para a promoção da densificação adequada à obtenção de esferas e aquela excessiva que ocasiona a aglomeração dos pellets individualizados, pode ser conseguida a fim de se atingir a situação ideal (Rowe, 1985; Hileman et al., 1993).

O tempo de esferonização revela-se um fator importante para a produção de pellets e os seus efeitos foram estudados para diversas formulações de misturas com celulose microcristalina. $\mathrm{O}$ aumento do diâmetro médio de pellets foi observado por O'Connor et al. (1984) e Wan et al. (1993) enquanto que Bianchini et al. (1992) observaram a produção de pellets mais homogêneos em termos de uma distribuição do tamanho dos pellets mais estreita. No entanto, o tempo de esferonização pode influenciar na obtenção de uma fração de tamanho de pellets específica (Malinowski, Smith, 1975; Chariot et al., 1987; Hasznos et al., 1992; Baert et al., 1993a; Ku et al., 1993; Umprayn et al., 1999).

Semelhante à velocidade, o tempo de esferonização pode ocasionar mudanças nas propriedades de empacota- mento dos pellets (Malinowski, Smith, 1975; Chapman et al., 1986; Hellén et al., 1993c; Hileman et al., 1993). Uma das características dos pellets usualmente avaliada é a esfericidade. Neste contexto, vários estudos apontam para a melhoria da esfericidade dos pellets concomitante ao aumento do tempo de residência do produto no esferonizador (Lövgren, Lundberg, 1989; Baert et al., 1993a; Hellén, Yliruusi, 1993; Hileman et al., 1993c; Hileman et al., 1993d; Wan et al., 1993; Umprayn et al., 1999). Outro aspecto observado para o aumento do tempo de esferonização de um produto de extrusão é a produção de pellets de melhor morfologia superficial, ou seja, a superfície do pellet torna-se mais lisa (Umprayn et al., 1999).

A carga de esferonização, ou seja, a massa de produto de extrusão destinada ao processamento de esferonização, constitui um outro fator relevante para o processo. Chariot et al. (1987) demonstraram que uma baixa carga de esferonização juntamente com o aumento da velocidade proporcionou diminuição na obtenção de pellets de uma fração de tamanho específica enquanto que alta carga de esferonização associada ao prolongamento do tempo de esferonização proporcionou aumento daquela mesma fração de tamanho de pellets. Hasznos et al. (1992) demonstraram o aumento do diâmetro médio de pellets para o aumento da carga de esferonização. Barrau et al. (1993) analisaram a influência da carga de esferonização na distribuição de tamanhos e qualidades dos pellets. Neste estudo, demonstrou-se que a distribuição de tamanho e o rendimento de uma fração específica $(1,25$ $1,60 \mathrm{~mm}$ ) não foram influenciados pela variação da carga de esferonização. O processamento com uma carga correspondente a $80 \%$ da capacidade do esferonizador maximizou o rendimento da fração de trabalho enquanto que uma carga mínima de $20 \%$ aumentou o rendimento da fração $0,8-1,00 \mathrm{~mm}$ e diminuiu o da fração de trabalho. No entanto, o aumento da carga de esferonização tornou os pellets mais rígidos, ao passo que se observou significativa diminuição da esfericidade dos mesmos. A redução da esfericidade dos pellets deveu-se ao aumento da pressão intergranular pelo aumento da carga de esferonização com conseqüente redução do efeito de contato do material em formação com a placa de esferonização. Hellén et al. (1993a, b) verificaram as influências das variáveis do processo de malaxagem e de esferonização na estabilidade da umidade do material e na morfologia, friabilidade, propriedades de empacotamento e de escoamento e no tamanho e distribuição de tamanhos dos pellets produzidos. Assim, demonstrou-se que o aumento da carga de esferonização juntamente com o aumento da velocidade e o prolongamento do tempo de esferonização resultaram no aumento dos volumes aparentes antes e após a compac- 
tação. Por outro lado, o mesmo aumento da carga associado ao prolongamento do tempo de esferonização induziu à diminuição do tamanho dos pellets produzidos.

A Tabela IV mostra, de forma resumida, a influência dos parâmetrso de esferonização na produção de pellets.

\section{Método de secagem}

Pouca atenção tem sido dada à natureza ou ao tempo do processo de secagem de pellets. De fato, apenas alguns estudos da literatura farmacêutica tratam dos efeitos do método de secagem e das condições de processo sobre as variações das propriedades físicas dos pellets produzidos.

Bataille et al. (1993) compararam a estrutura porosa, a dureza e a morfologia superficial de pellets obtidos a partir de mistura binária de celulose microcristalina e lactose, utilizando-se água como líquido de granulação e secos ou numa estufa de ventilação forçada ou num forno de microondas. Verificou-se que a secagem em estufa resultou em pellets de estrutura menos porosa e mais rígida e de superfície mais homogênea. Segundo estes autores, durante a secagem em estufa a migração da água para a superfície dos pellets foi conduzida mais lentamente, causando menos trauma à estrutura granular, ao passo que, na secagem por microondas, a profunda penetração destas levou à abrupta descarga de calor no interior da estrutura, resultando em quase imediata saída das moléculas de água e conseqüente enfraquecimento das ligações interpartículas traduzida na diminuição da dureza dos pellets. A mesma conclusão foi adotada por Sousa et al. (1996) para a comparação de pellets secos em estufa e em câmara de leito fluidizado. Dyer et al. (1994) compararam a secagem de pellets em leito estático (estufa) e em leito dinâmico (câmara de leito fluidizado). A formulação de pellets incluiu celulose microcristalina, lactose, ibuprofeno e água como líquido de granulação. Verificou-se efeito significativo do método de secagem sobre as propriedades dos pellets produzidos sendo aqueles secos em leito estático os que exibiram maior resistência mecânica e menor elasticidade. Alem disto, verificou-se que o método de secagem e, conseqüentemente, a taxa de secagem em leito estático resultaram em pellets de superfície mais lisa, em comparação aos resultantes da secagem em leito dinâmico.

A influência do método de secagem empregado no processo de peletização pode ter conseqüências na adequabilidade dos pellets para o posterior revestimento com película. Kleinebudde (1994a, 1994b) investigou a relação entre a formulação e o método de secagem de pellets no que diz respeito ao tamanho das partículas, contração, intumescimento, porosidade, friabilidade, desagregação e dissolução. Os pellets preparados incluíam um de três princípios ativos e a celulose microcristalina com ou sem baixa substituição por hidroxipropilcelulose. Os métodos de secagem de pellets investigados foram: secagem por congelamento, leito estático e leito fluidizado. Os pellets secos em leito fluidizado ou em leito estático mostraram o fenômeno de contração da estrutura, enquanto aqueles secos por via de congelamento se mostraram de tamanho comparável ao que apresentavam antes da secagem, embora com altas porosidades. $\mathrm{O}$ método de secagem não mostrou qualquer influência na desagregação dos pellets. Quando submetidos ao teste de dissolução, os pellets secos por via de congelamento mostraram razão de dissolução da substância ativa maior em comparação àqueles secos em leito fluidizado e o intumescimento foi proporcional à contração durante a secagem. O efeito da secagem sobre a porosidade de pellets de celulose microcristalina usando-se água ou mistura água/ etanol (25:75\%) foi estudado por Berggren, Alderborn (2001a). Esses autores verificaram que os pellets preparados com diferentes tipos de líquido de granulação apresentavam contração da estrutura e densificação durante a secagem. No entanto, e apesar de ambos os tipos de pellets terem apresentado porosidades anteriores à secagem similares, após a secagem os pellets preparados com a solução

TABELA IV - Influência dos parâmetros de esferonização na produção de pellets

\begin{tabular}{lllll}
\hline Esferonização & Seleção dos parâmetros & Velocidade de esferonização & Tempo de esferonização & Carga de esferonização \\
\hline Configuração da placa & & Velocidade de rotação da & Influência na distribuição & Influência na distribuição de \\
de esferonização: & $\bullet$ Velocidade & placa de esferonização: & de tamanho dos pellets & tamanho dos pellets (o \\
Não há estudos que & $\bullet$ Tempo & Influencia a distribuição de & (quanto maior o tempo & aumento da carga diminui a \\
indiquem a melhor & $\bullet$ Carga & tamanho dos pellets & maior a esfericidade e o & esfericidade e a dureza dos \\
configuração. & & (seu aumento diminui o & escoamento dos pellets e & pellets) \\
& diâmetro dos pellets e & melhoria da morfologia & \\
& aumenta a produção & superficial) & & \\
& de pós finos). & & \\
\hline
\end{tabular}


TABELA V - Influência dos parâmetros de secagem na produção de pellets

\begin{tabular}{llll}
\hline Secagem & Leito de secagem & Leito estático & Leito dinâmico \\
\hline $\begin{array}{l}\text { Temperatura de secagem: } \\
\text { Ambiente }\end{array}$ & Grande influência nas & Estufa (com circulação forçada & Câmara de leito fluidizado. \\
Elevada & $\begin{array}{l}\text { características dos pellets } \\
\text { (porosidade, dureza, tamanho e }\end{array}$ & Forno microondas. & \\
$\begin{array}{l}\text { Controle da temperatura do } \\
\text { ambiente de secagem). }\end{array}$ & morfologia de superfície). & & \\
\hline
\end{tabular}

etanólica foram maiores que aqueles preparados apenas com água. Subseqüentemente, Berggren, Alderborn (2001b) avaliaram os efeitos da razão de secagem em leito estático sobre a esfericidade, porosidade e o comportamento de compressão de pellets. Os pellets de celulose microcristalina foram preparados com soluções etanólicas de diferentes concentrações. Observou-se que a secagem dos pellets ocorreu numa razão decrescente e a redução no conteúdo de líquido em função do tempo obedeceu a relação de primeira ordem. A esfericidade e a morfologia superficial dos pellets não foram afetadas pela razão de secagem, entretanto, o aumento da razão de secagem resultou em pellets mais porosos. Perez e Rabiskova (2002) avaliaram a fase de secagem de pellets usando diferentes técnicas com variação da temperatura. De forma semelhante a estudos anteriores, observou-se que o aumento da temperatura de secagem acarretou processo de contração da estrutura dos pellets. A secagem em leito fluidizado resultou em pellets ligeiramente menores em comparação àqueles secos em estufa com ventilação forçada, provavelmente devido ao constante movimento das partículas no leito fluidizado. A Tabela $\mathrm{V}$ resume a influência dos parâmetros de secagem na produção de pellets.

\section{CONSIDERAÇÕES FINAIS}

Em conclusão, considerações devem ser tomadas em relação às distintas fases do processo de peletização por extrusão e esferonização. Assim, a revisão aqui apresentada e que relaciona os parâmetros de formulação e processo, incluindo-se equipamentos e variáveis correspondentes, permite relacionar os aspectos relevantes que irão influenciar de maneira mais ou menos significativa as características finais de pellets de acordo com o fim pretendido para essas multi-unidades. Alguns aspectos apontados no texto necessitam de estudos mais pormenorizados que possam esclarecer ou mesmo criar alternativas para o melhor processamento e a conseqüente produção de pellets de características aceitáveis. Visto assim, as tabelas apresentadas exibem os diferentes aspectos abordados e a relevância para cada um deles.

\section{AGRADECIMENTOS}

Helton Santos agradece à Fundação Para a Ciência e a Tecnologia, em Portugal, pelo apoio financeiro sob a forma da bolsa de doutoramento BD/18171/98.

\section{ABSTRACT}

\section{Production of pellets by pharmaceutical extrusion and spheronisation, Part I. Evaluation of Technological and formulation variables}

The pelletisation process consists of the agglomeration of fine powders of a drug substance and excipients into spherical units. These units are referred as pellets and differ from those obtained from the granulation process in terms of their physical characteristics. One of the pelletisation processes usually applied for production of pellets comprising an active drug is based on two fundamental unit operations: extrusion and spheronisation. The present work intends to describe and revise the literature of the so-called extrusion and spheronisation process regarding the implication of the technological and formulation parameters in the production of pellets.

UNITERMS: Extrusion. Spheronisation. Pellets.

\section{REFERÊNCIAS BIBLIOGRÁFICAS}

ALVAREZ, L.; CONCHEIRO, A.; GÓMES-AMOZA, J.L.; SOUTO, C.; MARTÍNEZ-PACHECO, R. Powdered cellulose as excipient for extrusionspheronization pellets of a cohesive hydrophobic drug. Eur. J. Pharm. Biopharm., v.55, p.291-295, 2003.

BAERT, L.; REMON, J.P. Influence of amount of granulation liquid on the drug release rate from pellets made by extrusion-spheronisation. Int. J. Pharm., v.95, p.135-141, 1993. 
BAERT, L.; FANARA, D.; DE BAETS, INICIAL?; REMON, J.P. Instrumentation of a gravity feed extruder and the influence of the composition of binary and ternary mixtures on the extrusion forces. J. Pharm. Pharmacol., v.43, p.745-749, 1991.

BAERT, L.; FANARA, D.; REMON, J.P.; MASSART, D. Correlation of extrusion forces, raw materials and sphere characteristics. J. Pharm. Pharmacol., v.44, p.676-678, 1992a.

BAERT, L.; REMON, J.P.; KNIGHT, P.; NEWTON, J.M. A comparison between the extrusion forces and sphere quality of a gravity feed extruder and a ram extruder. Int. J. Pharm., v.86, p.187-192, 1992 b.

BAERT, L.; VERMEERSCH, H.; REMON, J.P.; SMEYERS-VERBEKE, J.; MASSART, D.L. Study of parameters important in the spheronisation process. Int. J. Pharm., v.96, p.225-229, 1993a.

BAERT, L.; REMON, J.P.; ELBERS, J.A.C.; VAN BOMMEL, E.M.G. Comparison between a gravity feed extruder and a twin screw extruder. Int. J. Pharm., v.99, p.7-12, 1993 b.

BAINS, D.; BOUTELL, S.L.; NEWTON, J.M. The influence of moisture content on the preparation of spherical granules of barium sulphate and microcrystalline cellulose. Int. J. Pharm., v.69, p.233-237, 1991.

BARRAU, J.P.; BATAILLE, B.; JACOB, M. The influence of spheronizer load in extrusion-spheronization. Pharm. Tech. Int. Biophys., v.5, p.66-70, 1993.

BATAILLE, B.; LIGARSKI, K.; JACOB, M.; THOMAS, C.; DURU, C. Study of the influence of spheronisation and drying conditions on the physical-mechanical properties of neutral spheroids containing Avicel PH 101 and lactose. Drug Dev. Ind. Pharm., v.19, p.653-671, 1993.

BASIT, A.W.; NEWTON, J.M.; LACEY, L.F. formulation of ranitidine pellets by extrusion spheronisation with little or no microcrystalline cellulose. Pharm. Dev. Technol., v.4, n.4, p.499-505, 1999.

BECHGAARD, H.; HEGERMANN NIELSEN, G. Controlled-release multiple-units and single-unit doses. A literature review. Drug Dev. Ind. Pharm., v.4, p.53-67, 1978.
BERGGREN, J.; ALDERBORN, G. Drying bahaviour of two sets of microcrystalline cellulose pellets. Int. J. Pharm., v.219, p.113-126, 2001a.

BERGGREN, J.; ALDERBORN, G. Effect of drying rate on porosity and tabletting behaviour of cellulose pellets. Int. J. Pharm., v.227, p.81-96, 2001 b.

BIANCHINI, R.; BRUNI, G., GAZZANIGA, A.; VECCHIO, C. Influence of extrusion-spheronisation processing on the physical properties of d-indobufen pellets containing $\mathrm{pH}$ adjusters. Drug Dev. Ind. Pharm., v.18, p.1485-1503, 1992.

BRIQUET, F.; BROSSARD, C.; SER, J.; DUCHÊNE, D. Optimisation de la formulation par extrusionsphéronisation de microgranules matriciels à libération prolongée. S.T.P. Pharm., v.2, p.986-994, 1986.

CHARIOT, M.; FRANCÈS, J.; LEWIS, G.A.; MATHIEU, D.; PHAN TAN LUU, R.; STEVENS, H.N.E. A factorial approach to process variables of extrusionspheronisation of wet powder masses. Drug Dev. Ind. Pharm., v.13, p.1639-1649, 1987.

CONINE, J.W.; HADLEY, H.R. Preparation of small solid pharmaceutical spheres. Drug Cosmet. Ind., v.106, p.3841, 1970.

DIETRICH, R. Food technology transfers to pellet production. Manuf. Chem., v.60, p.29-33, 1989.

DYER, A.M.; KHAN, K.A.; AULTON, M.E. Effect of the drying method on the mechanical and drug release properties of pellets prepared by extrusion-spheronisation. Drug Dev. Ind. Pharm., v.20, p.3045-3068, 1994.

EL SALEH, F.; JUMAA, M.; HASSAN, I.; KLEINEBUDDE, P. Influence of cellulose type on the properties of extruded pellets II. Production and properties of pellets. S.T.P. Pharma Sci., v.10, n.5, p.379$385,2000$.

ELBERS, J.A.C. ; BAKKENES, H.W.; FOKKENS, J.G. Effect of amount and composition of granulation liquid on mixing, extrusion and spheronization, Drug Dev. Ind. Pharm., v.18, p.501-517, 1992.

ESKILSON, C. Controlled release by microencapsulation. Manuf. Chem. v.56, p.33-39, 1985. 
FIELDEN, K.E.; NEWTON, J.M.; ROWE, R.C. The effect of lactose particle size on the extrusion properties of microcrystalline cellulose-lactose mixture. J. Pharm. Pharmacol., v.41, p.217-221, 1989.

FIELDEN, K.E.; NEWTON, J.M.; ROWE, R.C. The effect of lactose particle size on spheronisation of extrudate processed by a ram extruder. Int. J. Pharm., v.81, p.205224, 1992a.

FIELDEN, K.E.; NEWTON, J.M.; ROWE, R.C. A comparison of the extrusion and spheronisation behaviour of wet powder masses processed by a ram extruder and a cylinder extruder. Int. J. Pharm., v.81, p.225-233, 1992b.

FIELDEN, K.E.; NEWTON, J.M.; ROWE, R.C. The influence of moisture content on spheronisation of extrudate processed by a ram extruder. Int. J. Pharm., v.97, p.79-92, 1993.

FUNCK, J.A.B; SCHWARTZ, J.B.; REILLY, W.J.; GHALI, E.S. Binder effectiveness for beads with high drug levels. Drug Dev. Ind. Pharm., v.17, p.1143-1156, 1991.

GOODHART, F.W.; DRAPER, J.R.; NINGER, F.C. Design and use of a laboratory extruder for pharmaceutical granulations. J. Pharm. Sci., v.62, p.133-136, 1973.

GOSKONDA, S.R.; UPADRASHTA, S.M. Avicel RC-591/ Chitosan beads by extrusion-spheronisation technology. Drug Dev. Ind. Pharm., v.19, p.915-927, 1993.

GOSKONDA, S.R.; HILEMAN, G.A.; UPADRASHTA, S.M. Controlled release pellets by extrusionspheronisation. Int. J. Pharm., v.111, p.89-97, 1994.

HARRISON, P.J.; NEWTON, J.M.; ROWE, R.C. Flow defects in wet powder mass extrusion. J. Pharm. Pharmacol., v.37, p.81-83, 1985a.

HARRISON, P.J.; NEWTON, J.M.; ROWE, R.C. The characterization of wet powder masses suitable for extrusion-spheronisation. J. Pharm. Pharmacol., v.37, p.686-691, $1985 b$.

HARRISON, P.J. ; NEWTON, J.M.; ROWE, R.C. The application of capillary rheometer to the extrusion of wet powder masses. Int. J. Pharm., v.35, p.237-242, 1987.
HASZNOS, L.; LANGER, I.; GYARMATHY, M. Some factors influencing pellet characteristics made by extrusion-spheronisation process Part I: Effects on size characteristics and moisture content decrease of pellets. Drug Dev. Ind. Pharm., v.18, p.409-437, 1992.

HELLÉN, L.; RITALA, M.; YLIRUUSI, J.; PALMROOS, P.; KRISTOFFERSSON, E. Process variable of the radial screen extruder: I. Production capacity of the extruder an properties of the extruder. Pharm. Tech. Int. Biophys., v.4, p.50-60, 1992.

HELLÉN, L.; YLIRUUSI, J. Process variables of instant granulator and spheroniser: III. Shape and shape distribution of pellets. Int. J. Pharm., v.96, p.217-223, 1993.

HELLÉN, L.; YLIRUUSI, J.; MUTTONEN, E.; KRISTOFFERSSON, E. Process variable of the radial screen extruder: II. Size and size distributions of pellets. Pharm. Tech. Int. Biophys., v.5, p.44-53, 1993 a.

HELlÉN, L.; YLIRUUSI, J.; MERKKU, P.; KRISTOFFERSSON, E. Process variable of the radial screen extruder: III. Shape, surface, and flow properties of pellets. Pharm. Tech. Int. Biophys., v.5, p.38-48, 1993 b.

HELLÉN, L.; YLIRUUSI, J.; MERKKU, P.; KRISTOFFERSSON, E. Process variable of instant granulator and spheroniser: I. Physical properties of granules, extrudate and pellets. Int. J. Pharm., v.96, p.197-204, 1993c.

HELLÉN, L.; YLIRUUSI, J.; KRISTOFFERSSON, E. Process variable of instant granulator and spheroniser: II. Size and size distributions of pellets. Int. J. Pharm., v.96, p.205-216, 1993d.

HICKS, D.C.; FREESE, H.L. Extrusion and spheronizing equipment. Pharmaceutical Pelletization Technology, New York, Basel: Marcel Dekker Inc., 1989. p.71-100.

HILERMAN, G.A. ; GOSKONDA, S.R. ; SPALITTO, A.J.; UPADRASHTA, S.M. A factorial approach to high dose product development by an extrusion-spheronisation process. Drug Dev. Ind. Pharm., v.19, p.483-491, 1993.

IYER, R.M.; AUGSBURGER, L.L.; POPE, D.G.; SHAH, R.D. Extrusion/soheronization-effect of moisture content and spheronisation time on pellet characteristics. Pharm. Dev. Technol., v.1, n.4, p.325-331, 1996. 
JOVER, I.; PODCZECK, F.; NEWTON, J.M. Evaluation, by statistical designed experiment, of an experimental grade of microcrystalline cellulose, Avicel 955, as a technology to aid production of pellets with high drug loading. J. Pharm. Sci., v.85, p.700-705, 1996.

JUNNILA, R.; PALVIAINEN, P.; HEINÄMÄKI, J.; MYLLÄRINEN, P.; FORSSELL, P.; YLIRUUSI, J. Waxy corn starch: a potent cofiller in pellets produced by extrusion-spheronisation. Pharm. Dev. Tech., v.5, n.1, p.67-76, 2000.

KLEINEBUDDE, P. Shrinking and swelling properties of pellets containing microcrystalline cellulose and low substituted hydroxipropylcellulose: I. Shrinking properties. Int. J. Pharm., v.109, p.209-219, 1994a.

KLEINEBUDDE, P. Shrinking and swelling properties of pellets containing microcrystalline cellulose and low substituted hydroxipropylcellulose: II. Swelling properties. Int. J. Pharm., v.109, p.221-227, 1994b.

KLEINEBUDDE, P.; LINDNER, H. The powderconsumption-controlled extruder: A tool for pellets production. J. Pharm. Pharmacol., v.46, p.542-546, 1994.

KU, C.C.; JOSHI, Y.M.; BERGUM, J.S.; JAIN, N.B. Bead manufacture by extrusion-spheronisation - A statistical design for process optimization. Drug Dev. Ind. Pharm., v.19, p.1505-1519, 1993.

LANTZ, R.J.; MANFORD, J. Method for preparing sustained release pellets and products thereof. US Patent 3,146,167, Aug. 25, 1964. 4p.

LAW, M.F.L.; DEASY, P.B. Use of hydrophilic polymers with microcrystalline cellulose to improve extrusionspheronisation. Eur. J. Pharm. Biopharm., v.45, p.57-65, 1998.

LINDNER, H.; KLEINEBUDDE, P. Use of powdered cellulose for the production of pellets by extrusion/ spheronisation. J. Pharm. Pharmacol., v.46, p.2-7, 1994.

LÖVGREN, K; LUNDBERG, P.J. Determination of sphericity of pellets prepared by extrusion-spheronisation and the impact of some process parameters. Drug Dev. Ind. Pharm., v.15, p.2375-2392, 1989.
MALINOWSKI, H.J.; SMITH, W.E. Use of factorial design to evaluate granulations prepared by spheronisation. $J$. Pharm. Sci., v.64, n.10, p.1688-1692, 1975.

MILLILI, G.P.; SCHWARTZ, J.B. The strength of microcrystalline cellulose pellets: the effect of granulating with water/ethanol mixtures. Drug Dev. Ind. Pharm., v.16, p.1411-1426, 1990.

MIYAKE, Y.; SHINODA, A.; FURUKAWA, M.; UESUGI, K.; NASU, T. Spheronizing mechanism and properties of spherical granules. Yakuzaigaku, v.33, p.161-166, 1973.

NAKAHARA, N. Method and apparatus for making spherical granules. US Patent 3,277,520, Oct. 11, 1966, 6p.

NEAU, S.H.; CHOW, M.Y.; DURRANI, M.J. Fabrication and characterization of extruded and spheronized beads containing carbopol ${ }^{\circledR}$ 974P, NF resin. Int. J. Pharm., v.131, p.47-55, 1996.

NEAU, S.H.; CHOW, M.Y.; HILEMAN, G.A.; DURRANI, M.J.; GHEYAS, F.; EVANS, B.A. Formulation and process considerations for beads containing carbopol ${ }^{\circledR}$ 974P, NF resin made by extrusion-spheronisation. Int. $J$. Pharm., v.199, p.129-140, 2000.

NEWTON, J.M. ; CHOW, A.K.; JEEWA, K.B. The effect of excipient source on spherical granules made by extrusion-spheronisation. Pharm. Tech. Int. Biophys., v.4, p.52-58, 1992.

NOCHÉ, C.; HUET DE BAROCHEZ, B.; BROSSARD, C.; HORVATH, S.; CUINÉ, A. Optimizing the manufacturing process for controlled release pellets. Pharm. Tech. Eur., v.6, n.4, p.39-46, 1994.

NÜRNBERG, E.; WUNDERLICH, J. Manufacturing pellets by extrusion and spheronisation (Part I). Pharm. Tech., v.11, p.41-47, 1999a.

NÜRNBERG, E.; WUNDERLICH, J. Manufacturing pellets by extrusion and spheronisation (Part II). Pharm. Tech., v.11, p.32-34, 1999b.

O'CONNOR, R.E. ; HOLINEJ, J.; SCHWARTZ, J.B. Spheronisation: I. Processing and evaluation of spheres prepared from commercially available excipient. Am. J. Pharm., v.156, p.80-87, 1984. 
PERÉZ, J.P.; RABIŠKOVÁ, M. Influence of the drying technique on theophylline pellets prepared by extrusionspheronisation. Int. J. Pharm., v.242, p.349-351, 2002.

PINTO, J.F.; BUCKTON, G.; NEWTON, J.M. The influence of four selected processing and formulation factors on the production of spheres by extrusion and spheronisation. Int. J. Pharm., v.83, p.187-196, 1992.

PINTO, J.F. Avaliação de duas celuloses microcristalinas na produção de grânulos por extrusão e esferonização. Rev. Port. Farm., v.48, p. 113-118, 1998.

REYNOLDS, A.D. A new technique for the production of spherical particles. Mfg Chem. Aerosol News, v.41, p.4043, 1970.

ROWE, R.C. Spheronisation: a novel pill-making process? Pharm. Int., v.6, p.119-123, 1985.

SANTOS, H. ; VEIGA, F.; PINA, M.; PODCZECK, F.; SOUSA, J. Physical properties of chitosan pellets produced by extrusion-spheronisation: influence of formulation variables. Int. J. Pharm., v.246, p.153-169, 2002.

SCHMIDT, C.; KLEINEBUDDE, P. Influence of the granulation step on pellets prepared by extrusion/ spheronisation. Chem. Pharm. Bull., v.47, p.405-412, 1999.

SONAGLIO, D.; BATAILLE; B. ; ORTIGOSA, C. ; JACOB, M. Factorial design in the feasibility of production microcel MC 101 pellets by extrusion/ spheronization. Int. J. Pharm., v.115, p.53-60, 1995.

SONAGLIO, D.; BATAILLE, B. ; JACOB, M. Effects of extrusion and formulation parameters on the production of paracetamol-microcrystalline cellulose extrudate. Pharm. Acta Helv., v.72, p.69-74, 1997.

SOUSA, J.J.; SOUSA, A.; NEWTON, J.M. Produção e controlo de pellets de propranolol, $\mathrm{HCl}$ I. Obtenção de pellets activos por extrusão/esferonização. Rev. Port. Farm., v.45, p.60-69, 1995a.

SOUSA, J.J.; SOUSA, A.; NEWTON, J.M. Produção e controlo de pellets de propranolol, HCl II. Revestimento por filme. Rev. Port. Farm., v.45, p.60-69, 1995b.
SOUSA, J.J.; SOUSA, A.; PODCZECK, F.; NEWTON, J.M. Influence of process conditions on drug release from pellets. Int. J. Pharm., v.144, p.159-169, 1996.

SOUSA, J.J.; SOUSA, A.; PODCZECK, F.; NEWTON, J.M. Factors influence the physical characteristics of pellets obtained by extrusion-spheronization. Int. J. Pharm., v.232, p.91-106, 2002a.

SOUSA, J.J.; SOUSA, A.; PODCZECK, F.; NEWTON, J.M. The influence of core materials and film coating on the drug release from coated pellets. Int. J. Pharm., v.233, p.111-122,2002b.

SWARBRICK, J.; BOYLAN, J.C. Economic characteristics of the $R \& D$-intensive pharmaceutical industry to fermentation processes. New York: Marcel Dekker, 1992.p.395-442.

THOMA, K.; ZIEGLER, I. Investigation on the influence of the type of extruder for pelletization by extrusionspheronisation. I. Extrusion behavior of formulations. Drug Dev. Ind. Pharm., v.24, p.401-411, 1998a.

THOMA, K.; ZIEGLER, I. Investigation on the influence of the type of extruder for pelletization by extrusionspheronisation. II. Sphere characteristics. Drug Dev. Ind. Pharm., v.24, p.413-422, 1998b.

UMPRAYN, K.; CHITROPAS, P.; AMAREKAJORN, S. Influence of process variables on physical properties of pellets using extruder and spheronizer. Drug Dev. Ind. Pharm., v.25, p.45-61, 1999.

VARSHOSAZ, J.; KENNEDY; R.A.; GIPPS, E.M. Use pf enteric polymers for production of microspheres by extrusion-spheronisation. Pharm. Acta Helv., v.72, p.145$152,1997 \mathrm{a}$.

VARSHOSAZ, J.; KENNEDY, R.A.; GIPPS, E.M. Effect of binder and granulating liquid on phenylbutazone pellets prepared by extrusion-spheronisation. Drug Dev. Ind. Pharm., v.23, p.611-618, $1997 \mathrm{~b}$.

WAN, L.S.C.; HENG, P.W.S. ; LIEW, C.V. Spheronization conditions on spheroids shape and size. Int. J. Pharm., v.96, p.59-65, 1993.

Recebido para publicação em 21 de outubro de 2003. Aceito para publicação em 08 de outubro de 2004. 